\title{
Concussion Blindness
}

\author{
One of the Typical Developments of the War
}

\section{By Arthur F. Hertz, M.D. and Arthur W. Ormond, F.R.B.S. Eng.}

ONE of the principal ocular features of the present war is the number of cases of functional blindness due to the violent explosions caused by high explosive shells, bombs, hand-grenades, etc. These cases may or may not have sustained definite organic injuries, but the clinical symptoms characterizing their functional nature are very clearly marked. Usually the patient has been rendered unconscious by an explosion in his close vicinity, and on regaining consciousness he finds that he is unable to see. When examined he presents the following symptoms: The eyes are kept closed, the lids may be frequently "fluttered," or as one man stated, "he could not keep his eyes from twinkling." On attempting to open the lids the patient resists forcibly by means of his orbicularis; when this is overcome to a sufficient extent to see the globes, they are found to be rolled forcibly upward, and the pupils are always kept covered by the lids; he has great difficulty in looking downward, and complains of pain and photophobia, and shows marked fatigue as a result of the examination. In some cases I (A. W. O.) have noticed an acceleration of the pulse-rate and also perspiration. The photophobia is not, however, really influenced by light, as the condition does not diminish in very subdued illumination. These patients never move about as blind men would; they invariably avoid hurting themselves, but all the same they never relax, even if watched for weeks at a time, the groping action of people with extremely defective sight, and judged by every test they maintain this condition indefinitely and are undoubtedly psychically blind. The pupils react normally and the fundus shows no definite change. There is no and the fundus shows no definite change. There is no
difficulty in differentiating them from malingerers, as they pass through long periods of real mental distress and serious discomfort. These cases vary enormously in severity; some recover rapidly, others seem to go on indefinitely if not treated, or treated unsuccessfully. Any lack of recognition of the condition in the early stages enormously prejudices the prognosis. One patient having been told that he was blind remained so for several months, whereas probably if it had been recognized earlier that he was not blind and would recover he would have done so much more rapidly.

Early in the war I treated these cases in several ways, all with disappointing results; some of the slighter cases certainly did recover, but they recovered in spite of treatment and not on account of it. The main principles on which I worked were rest, tonics, deprivation or punishments, such as abstention from tobacco, confinement to bed or in isolation rooms, persuasion, encouragement, counter-irritation, talking, etc., but all these means were comparatively ineffective until suggestion and hypnosis were tried. In August, 1915, I thought it would be advisable to try suggestion, although I had a strong personal prejudice against its use, but when later on these cases still remained on my hands I consulted with Dr. Hertz, and we decided to start the hypnotic treatment. The method employed was to have the men singly in a darkened room, quiet, and resting in the most comfortable armchair the ward could provide. They were instructed as to what was to be attempted, and no demur was ever made by any of them, but, on the contrary, was ever made by any of them, but, on the contrary,
after the first experience they were always eager to continue the treatment. The patient had his eyes closed, of course, so that the assistance of light and fixation could not be obtained; but he was told to think of something pleasant and agreeable, not to take the slightest notice of the operator, to relax his mind by attempting to stop all incoming thoughts and to make his mind, as far as all incoming thoughts and to make his mind, as far as
possible, a blank. We then used the usual methods of possible, a blank. We then used the usual methods of
inducing hypnosis. In some cases-for example, Case 1 -the hypnotic condition was obtained, but not in all and I do not think it at all necessary to obtain complete unconsciousness; the main thing to be arrived at is to obtain a relaxation of the patient's mind and his muscles and to overcome his unconscious resistance.

The treatment is carried on thus for a few minutes, and having obtained the sleepiness or light hypnosis necessary, the patient is subjected to a forcible suggestion from the operator, who reiterates the patient's ability to see and to open his eyes, and to assert very vehemently that he is not blind as he imagines, but that his eyes are perfectly sound and that he can see.

The results have varied considerably as to rapidity of recovery, but all have shown marked improvement, the most drastic being that of the patient in Case 1, the most resistant being the deaf and blind man (Case 5). Cases of this nature have been constantly arriving from France and Gallipoli, but I here insert the notes sent to me by Dr. Hertz immediately previous to his departure for
Alexandria, as they were the earliest ones with which we dealt and are quite typical, and in all of them, except in the last case, Dr. Hertz collaborated with me in their treatment; they, however, only represent a small proportion of the total number of cases.

NOTES OF CASES BY DR. HERTZ.

“Case 1.--The patient, aged twenty-two, was looking over a parapet on July 18th, 1915, when a shell struck the sandbags in front of him. He remembers the sand being thrown up into his eyes and his falling back so that he knocked his head. He remained unconscious for twenty-four hours. When he regained consciousness $h$ found that he was completely blind, except that he could just distinguish light from darkness with his left eye His eyes felt very sore and his eyelids were constantly moving up and down; he was partially deaf and had severe headache. His hearing soon returned, and th headache rapidly improved, but the condition of his eye had not altered when I first saw him with Mr. Ormond on September 17th. He was quite blind and there was a constant flicker of his eyelids, which were kept almost closed. On forcibly opening his eyes they were found to be turned so far upward that it was difficult to see even the iris. A few fragments of sand were still em bedded in the conjunctiva but not in the cornea; there was no inflammation present.

"The patient was easily hypnotized, and while asleep he was told that he would be able to see when he woke up The moment he awoke the suggestion was repeated very forcibly, and his eyes were held open. He cried out that he could see, tears ran down his cheeks, and he fell on his knees in gratitude, as he thought that he was permanently blind, and believed that his sight had been restored by a miracle. When seen again on Spetember 20th th external appearance of his eyes was normal, and he said that he was able to see as well as he had ever done. $\mathrm{Mr}$ Ormond, however, found that there was some opacity of the vitreous of the left eye, secondary to hemorrhage from a retinal vessel, which had ploughed its way forward; this was doubtless a result of injury at the time of the explosion. There has been no return of symptoms, and the patient was well in every way when I last saw him on September 30th. His vision was $6 / 6$ in the right eye and $6 / 36$ in the left.

Case 2.-The patient had an attack of blindness resulting from conjunctivitis caused by a sandstorm when in Egypt early in 1915. He recovered from this after ten weeks, and six weeks later went to the Dardanelles. On July 12 th a shell struck a sandbag immediately in fron of him and the sand flew into his eyes. He did not lose consciousness, but his sight gradually became more and more deficient until at the end of ten days he was only just able to distinguish light from darkness. Very slight improvement occurred spontaneously, but his condition when seen on September 17th was identical with that of the patient in the preceding case, a few pieces of gri being still embedded in the conjunctiva, although ther was no inflammation.

"The patient was easily hypnotized, but there was very little improvement at the moment. Considerable improvement, however, occurred during the next three days. He was hypnotized on three more occasions; he could see perfectly well on September 30th, but still had some photophobia and wore dark glasses, as he could not avoid constantly blinking when they were removed. He was therefore hypnotized yet again, and it was suggested to him that the photophobia and blinking would now cease. The result was completely successful, as all symptom had disappeared by October 4th, although no attempt had been made to remove the grit from the conjunctiva. "Case 3.-The patient, aged twenty, was rendered unconscious for a few minutes as a result of the explosion of a shell near him on August 21st in the Dardanelles. Some of the powder was blown into his eyes, which were very sore when he regained consciousness, although he was still able to see quite well. During the next twenty four hours his vision became more and more impaired. The powder was removed from his eyes when he wa taken on board the hospital ship, and his eyes wer bandaged. After a few days he thought he would be able to see quite well if the bandages were removed, but the medical officer in charge told him that it would be dangerous to do so. During the voyage home he was not allowed to remove the bandages, and he became more and more convinced that this must be because the medical officer thought he was blind. The bandages had not been removed when he was admitted into the hospital on September 25th. When they were removed he wa found to be in exactly the same condition as the preceding patients. He could distinguish light from darkness, but was unable to see any thing, and he kept his eyes turned up and his eyelids closed and constantly contracting.

"On September 27 th he was hypnotized by Mr. Ormond, after which he found that he could see quite well, but the light still worried him and the blinking continued, though to a diminished extent. He completely recovered subsequently and returned to his depot.

"Case 4.-The patient, aged twenty-nine, was knocked over by a high explosive shell in the Dardanelles and remained unconscious for a considerable time. On coming round he found he could only distinguish light from darkness; there was no smarting of the eyes, but he constantly blinked. He had a slight headache, but was otherwise well. He began to improve about September 10th, so that he could recognize shadows passing in front of his eyes, but no further improvement occurred until he was hypnotized on September 18th. There was very slight improvement as the result of suggestion at the time, but when seen again on the 20th he said that he was beginning to recognize objects, and the blinking was less marked than before, but he still kept his eyeballs turned upward and his eyes almost closed. He was hypnotized again on September 20th and 25th, and when seen on the 30th his sight was quite normal and the blinking had completely ceased. Subsequent retinoscopic examination revealed the presence of a considerable degree of myopic astigmatism

"Case 5.-The patient was signaling from a gun limber on April 28th when he was blown up and remained unconscious for six days. There was no external wound, but on regaining consciousness he found that he was blind, except that he could just distinguish light from darkness; he was also completely deaf and was unable to speak. He regained his speech in June, after a fortsight and hearing remained unaltered.

"When I saw the patient on September 17th he could only be made to hear by shouting down an ear-trumpet; he kept his eyelids almost closed and constantly twitching with his eyeballs turned upward. He was extremely depressed, as he had been told by an aurist that he would never regain his hearing, as it was said that nerve deafness of such long duration could not improve, although the drums were intact. He concluded that the blindness would also be permanent. It was not easy to hypnotize him as he was unable to see, and all suggestions had to be shouted down his trumpet, but Mr. Ormond succeeded in doing this at the first attempt. When seen on September 20th he said that his sight was distinctly better, and he was able with difficulty to open his eyes. He was much more cheerful, particularly when we told him that his hearing would also return, as his auditory nerves were no more organically diseased than his optic nerves. On September 30th there was some further improvement, as he could see everything in the outer part of his left domestic worry, which no doubt prevented a more rapid improvement.

"Case 6.- The patient was unconsciousfor an hour after being blown up by a shell on August 7th. He was unable even to distinguish light from darkness when he recovered consciousness, but he very gradually improved. He was admitted into the hospital on August 22nd, after which improvement was much more rapid, and by the middle of September he had quite recovered without any special treatment.

"Case 7.-The patient, aged twenty, had never used his left eye, owing to an extreme degree of hypermetropia and amblyopia. When the other eye was covered he could only see very indistinctly with it, but in spite of this he managed to pass the medical examination when he entered the army. He was hit on the left side of the head by the butt of a rifle in June and was unconscious for a few minutes. When he regained consciousness he at once noticed that he could not see at all with his left eye, although he had hitherto been in the habit of neglecting the blurred image he saw with this eye. On August 10th he received a slight wound to his left thigh, but continued on duty. The wound had not completely healed, and was still somewhat painful when, on August 23rd, he was blown up by a high explosive shell. When he regained consciousness $\mathrm{h}$ e was being carried on a stretcher. The pain from his old wound drew his attention to his left leg, and he thought that he was unable to walk. When taken on the ship he found that this was the case, although there was no new injury of the leg. He also complained of severe pain above the left eye, which he 
kept covered by a shade, as he found that the least light greatly increased the headache; when the shade was removed he was unable to open the eye at all. For some time he was in an extremely excited condition, and he slept very badly owing to nightmares. His eye was kept covered by a shade during his journey home from the Dardanelles. On his arrival in England Mr. C. M. Ryley found that beyond the hypermetropia his left eye was normal, although he was quite unable to see anything with it.

"The patient was hypnotized on four different occasions. After the first he already slept better, the nightmares ceasing and the headache being less severe. On the second occasion, while still asleep, the shade was removed from his eye and he did not discover until half an hour after he woke up that it was no longer present although up to that time he said that the least light caused extreme discomfort and spasm of the eyelid. After the third treatment he found that he could see almost as well with his left eye as before he was hit on the head. Meanwhile, he was still unable to walk without crutches, although the wound in the leg had completely healed, and there was no physical cause to account for this. When he was hypnotized for the fourth time it was therefore suggested to him that he would be able to walk quite well, and he subsequently recovered entirely." These cases are typical of many others that have been
treated similarly; in fact, fresh cases of this same conditreated similarly; in fact, fresh cases of this same condi-
tion are arriving every week and the "suggestion" treatment has not failed to give marked improvement in every instance. Up to the present we have had no failures, although the patient in Case 5 has proved the most resistant, but his deafness and domestic trouble, together with the very unfortunate handling of the case in the early stages, have no doubt been responsible for this Mr. Francis Brook very kindly undertook the later stages of his treatment for me (A. W. O.) as owing to his greater experience in this work I thought he might obtain better results than I had effected. In November the patient was given an anæsthetic, and suggestion was tried during the stage of semi-consciousness, with marked success, as on the following day he opened his eyes voluntarily and has kept them open ever since. His speech and his sight has kept them open ever since. His speech and his sight having now retur
be long delaved.

Dr. Hertz and I trust that by publishing these cases Grestar attention may be drawn to these conditions, so that oven if treatment cannot be applied at once the cases may not be prejudiced unfavorably by injudicious handling.

It is probable that the presence of sand, grit, etc., in the eonjunctival saes of some of these patients may have been the cause of the "suggestion" of blindness, but it was not present in all cases, and recovery took place without its being removed; as a matter of fact, they were, when present, altembedded in the conjunctiva and did not produce any irritative symptoms at the time the patients were under treatment.-The Lancet.

\section{Uses of Tungsten}

THE great use of tungsten is as an alloy of high-speed steel-that is, steel used for making tools used in metalturning lathes running at high speed-to which tungsten imparts the property of holding its temper at ligher temperatures than will carbon steels. In such steels from 16 to 20 per cent of tungsten is used. Saw blades are made which contain 1 to 2 per cent tungsten. The use of tungsten in magnet steels has consumed large quantities, but this use seems to be derlining somewhat The now well-known ductile tungsten is used for incalldescent launs, which are fast displacing carbon lamps. Lately greatly improved lamps, in which the wire is wound in helices and in which the globes are filled with nitrogen, have brought the consumption of electricity down to $0.4-0.5$ watt per candle and have produced a close approach to white light. These lamps are fur. nished in candle powers up to 2,000. I'ndoubtedly the bulk of the research in the manufacture and use of ductile metallic tungsten has been carried out by the highly efficient corps of scientists under the direction of Dr. W. R. Whitney in the General Electric Company's wonderful research laboratories. Dr. C. G. Fink, of the company's staff, gives the probable or possible uses of worked tungsten as follows:

The ductile metal is practically insoluble in all of the common acids; its melting point is higher than that of any other metal; its tensile strength exceeds that of iron and nickel; it is paramagnetic; it can be drawn to smaller sizes than any other metal; and its specific gravity is 70 per cent higher than that of lead. It was natural that a metal with such striking properties as these should soon find application other than that for incandescent lamps.

Wrought tungsten hass been sulstituted with sulcess for platinum and platinum-iridium as contact points in

1 Metall. and Chem. Eng., vol. 10, pp. 580-581, 1912. A paper
delivered before the section of elcctro-chemistry, Eighth Internattional Congress, Applied Chemistry, Sept. 6, 1913. spark coils, voltage regulators, telegraph relays, etc. Th service far exceeds that for platinum and platinum iridium contacts due to the greater hardness, higher hea conductivity, and lower vapor pressure of tungsten as compared with platinum.

Electric laboratory furnaces with tungsten resister are of two types. In one a tungsten wire is wound on an aluminium tube in an air-tight box with a hydrogen atmosphere. In the second a tungsten metal tube takes the place of the helical carbon resister in an Arsen vacuum furnace.

Tungsten gauze is used successfully for separating solids from acid liquids in the laboratory. This gauze could well be used on a commercial scale; for example for the removal of sludge from copper refining baths, and for centrifugal apparatus in general whenever aci liquids or acid gases are dealt with. Furthermore, it might be used in apparatus such as described by Cottrell for the removal of sulphuric mist from gases.

Wrought tungsten targets for Roentgen tubes have proved to be one of the most interesting applications. For thermocouples the tungsten-molybdenum couple is not less interesting. The electromotive force increases with the temperature up to about $540 \mathrm{deg}$. Cent. (12 1/2 millivolts), then decreases and passes through 0 millivolts at about 1,300 deg. Cent. This couple is very convenient for high-temperature measurements in the tung sten-hydrogen furnace.

For standard weights tungsten is also well suited since wrought tungsten can be made so hard that it will reailily scratch glass and still be ductile; furthermore, the density is high (19.3 to 21.4) and it is unaffected by the atmosphere. Tungsten weights remain wonderfully constant.

Besides the applications of tungsten cited above, many others have been but partly worked out and others merely suggested. Owing to its chemical stability the finest sizes of wire down to 0.0002 inch or 0.0005 milli meter in diameter are well adapted for galvanomete suspensions and for cross hairs in telescopes. It ha also been suggested to use these fine wires in surgical operations in place of the coarser gold and silver wires. A further suggestion is the use of the wire in musical instruments.

Acid-proof dishes and tubes have been made out of tungsten; furthermore, tungsten wire recommends itself as a unit resistance, since it can be made absolutely pure, can be easily duplicated, and is not corroded.

Since tungsten is paramagnetic and elastic, it is being tried out in electrical meters, replacing the phosphor bronze springs. Similarly watch springs could be made which would never become magnetized. Finally, tungsten pen points, tungsten drawing dies, tungsten knif blades, tungsten reinforced asbestos curtains and fire proof coverings, etc., were mentioned.

TABLE OF PHYSICAI AND CHEMICAL PROPERTIES OF DUCTILE Density, 19.3 to 20.2 .

$$
\text { TUNGSTEN. }
$$

Tensile

Young's modulus of elasticity, 42,200 kilograms pe quare millimeter (steel 20,000).

Melting point, 3,177 deg. Cent. (Langmuir) ; 3,100 deg. $\pm 60 \mathrm{deg}$. Cent. (Pirani \& Meyer).

Boiling point, 3,700 deg. Cent.?

Thermal conductivity 0.35 gram. cal. per centimete

ner second per 1 degree (Pt. 0.166)

Expansion coefficient $4.3 \times 10^{-6}$ (Pt. $8.8 \times 10^{-6}$.)

Specific heat 0.0358 (Weiss).

Resistivity, hard : 6.2 microhms per cubic centimeter

and annealed 5.0 microlnms per cubic centimeter.

Temperature coefficient of resistance, 0.0051 ( 0 deee-170 degrees ).

Magnetic susceptibility: $+0.33 \times 10^{-6}$ (Honda); that is, practically nonmagnetic

Hardness 4.5 to 8.0 (Mohs scale)

Insoluble in $\mathrm{HC} 1, \mathrm{H}_{2} \mathrm{SO}_{4}, \mathrm{HNO}_{3}, \mathrm{HF}, \mathrm{NaOH}, \mathrm{KOH}$ (aq), and mixtures of $\mathrm{K}_{2} \mathrm{Cr}_{2} \mathrm{O}_{7}+\mathrm{H}_{2} \mathrm{SO}_{4}$, soluble in mixtures of $\mathrm{HF}$ and $\mathrm{HNO}_{3}$ and in fused nitrates and neroxides.

The boiling point of the metal has not yet been determined.-1tineral Resources of the U. S., 1913-Part II-IJ. S. Acological Survey.

\section{Sub-Aqueous Storage of Oil Fuel}

A RECENT issue of the Engineer contains a description of a method of storing oil fuel for submarines unde water, both to provide a secret and convenient fuel station, and to protect the supplies from guns and aircraft. and it may be inferred from the text that suc stations have been established, and are in operation by the liritisl sovermment. One of the larges mentioned is ill the form of a tank 150 feet long and 30 feet diameter, with hemispherical ends, which would carry $2,40 \mathrm{U}$ tons of liquid fuel, and could be submerged by admitting water to the compartments at the ends. To bring the vessel to the surface compressed air was introducel to force out about 30 tons of ballast water, or either oil or water could be pumped out through flexible tubes to make the vessel rise.

Another arrangement descrilied is a storage barge, which would not be wholly submerged. This would be a cylinder 450 feet long by 50 feet 9 inches mean diameter, and capable of containing 20,0000 tons of fuel. An nclosed passage ruming the entire length of the vessel would accommodate the valves and onerating mechanism, and would also furnish reserve buoyancy

It was also suggested that vessels and barges of simiar construction might he used for transporting fuel oil cross the Atlantic by towing.

\section{SCIENTIFIC AMERICAN SUPPLEMENT}

NEW YORK, SATURDAY, MARCH 11, 1916.

Published weekly by Munn \& Company, Incorporated Charles Allen Munn, President; Frederick Converse Beach, Secretary; Orson D. Munn, Treasurer;
all at 233 Broadway, New York

Entered at Post Office of New York, N. Y., as Second Class Matter Copyright 1916 by Munn \& Co., Inc.

The Scientific American Publications Scientific American Supplement (established 1876) per year $\$ 5.00$ The combined subscription rates and rates to foreign countries, including Canada, will be furnished upon application

Munn \& Co., Inc., 233 Broadway, New York

The purpose of the Supplement is to publish the more important announcements of distinguished technologists, to digest significant articles that appear in European publications, and altogether to reflect the most advanced thought in science and industry throughout the world.

Back Numbers of the Scientific American Supplement

SUPPLEMENTs bearing a date earlier than January 2nd, 1915, can be supplied by the H. W. Wilson Company, 39 Mamaroneck Avenue, White Plains, N. Y. Please order such back numbers from the Wilson Company. Supplements for January 2nd, 1915, and subsequent issues can be supplied at 10 cents each by Munn \& Co., Inc., 233 Broadway, New York.

$W_{E}$ wish to call attention to the fact that we are in a position to render competent services in every branch of patent or trade-mark work. Our staff is composed of mechanical, electrical and chemical experts. thoroughly trained to prepare and prosecute all patent applications, irrespective of the complex nature of the subject matter involved, or of the specialized, technical, or scientific knowledge required therefor.

We also have associates throughout the world, who assist in the prosecution of patent and trade-mark applications filed in all countries foreign to the United States.

MUnN \& Co.,

Patent Solicitors, 233 Broadway,
New York, N. Y.

Branch Office

25 F Street, N. W.,

Washington, D. C.

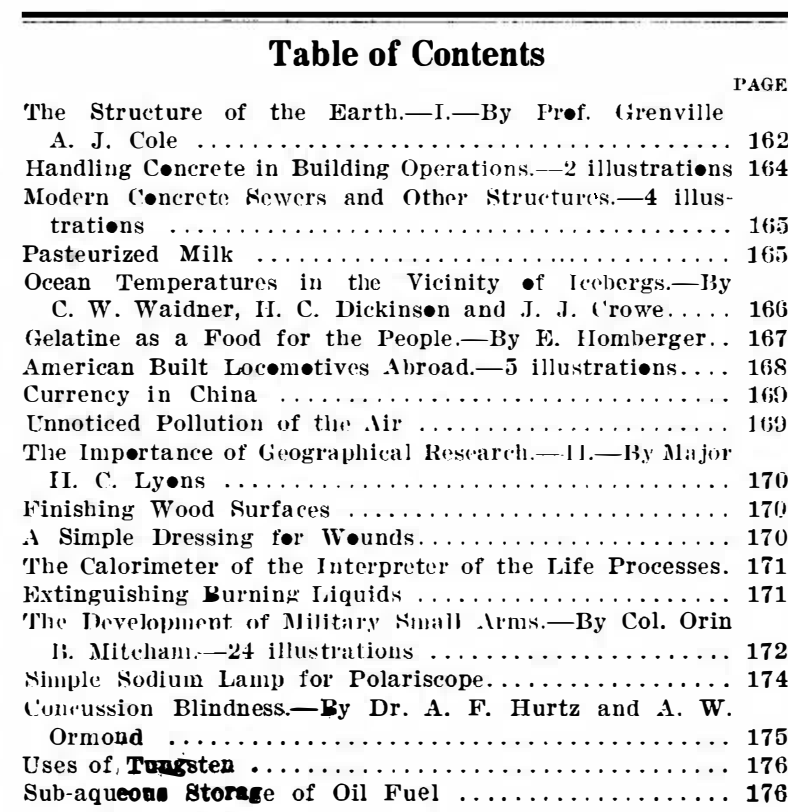

